\title{
JOURNAL
}

OF THE

EUROPEAN HONORS COUNCIL

Note

\section{Introduction: applying a research-based approach in talent development}

Pierre van Eijl1 ${ }^{1}$ Maarten Hogenstijn ${ }^{2}$

1. Utrecht University, the Netherlands

2. European Honors Council Board; Hanze University of Applied Sciences, Groningen, the Netherlands

Correspondence: journal@honorscouncil.eu

Published: 23 May 2018

\section{Introduction}

The Editorial Board is honored to present you the third issue of the Journal of the European Honors Council (JEHC). With the JEHC, we aim to share knowledge and good practices regarding honors programs and talent development programs in higher education. This third issue (volume 2, issue 1 ) is the result of an open call for papers.

Still, we can discern a common theme in this issue. The contributions show how a researchbased approach can be practically applied in talent development, both in the didactical approaches and the organizations of programs for talented students.

\section{The papers}

The issue contains three peer-reviewed papers.

The first contribution comes from France: 'An ambitious 5-year honors program in French universities: CMI-FIGURE.' Ramona Barbour Eisen, Yves Bertrand, Lamine Boubakar, JeanPierre Gesson, Sylvie Pautrot, and Rodolphe Vauzelle describe the 'Cursus Master en Ingénierie' (CMI) program, as well as the 'Formation à l'InGénierie par des Universités de Recherche' (FIGURE) university network, and analyze its development and place in the French higher education context. CMI is a 5-year academic program designed for the most ambitious students in systems engineering. Key features of the frame of reference established by the FIGURE network are selection of students based on high school records and interviews, a strong link with research from the start, $20 \%$ additional coursework compared to the supporting bachelors and masters, at least $25 \%$ of ECTS credits in applied learning situations, development of self-assessment skills, and compulsory international mobility. After completing a CMI program, the students receive a master's degree from their home university and a national certificate co-delivered by the university and the network. 
The second contribution comes from the Rotterdam University of Applied Sciences (RUAS) in The Netherlands and is titled 'Powerful Learning Environments: A Guide to Designing Innovation Labs,' written by Ineke Miltenburg and Ron Weerheijm. The RUAS Honors Program aims to encourage students to develop into excellent professionals. To do so, RUAS has developed a competence profile entitled 'Learning to Innovate.' This profile serves as a guide for designing a teaching approach that enables students to actively develop into such professionals. In this paper, the authors first explain the essence of an Innovation Lab or I-lab. Then, they present some additional considerations and various different approaches to designing a powerful learning environment like the I-Lab.

The third contribution, 'Implementing theory in the design of a professional development course for honors teachers: A Teacher's Road to Excellence,' comes from Hanze University of Applied Sciences Groningen, The Netherlands. The authors, Marjolein Heijne-Penninga, Inge Wijkamp, Maarten Hogenstijn, and Marca Wolfensberger, emphasize that teacher development courses should be based on research to promote their success and impact in practice. They translate the findings of research studies and theories into evidence-based design principles for a professional development course for honors teachers. This course was evaluated on the level of teacher reaction, teacher learning, outcomes, and organizational response. Nine design principles were formulated and translated into concrete actions resulting in the one-year course, 'A Teacher's Road to Excellence.' In an evaluation among participants, impact on honors teachers is clearly seen, and there are some signs of impact on student learning outcomes.

\section{The notes}

In addition to the three papers, this issue also contains three notes: shorter pieces showing good practices and/or preliminary findings.

The first two notes are closely interrelated, elaborating on two of the three pillars for honors didactics that were first formulated by Wolfensberger (2012). Students who are able and motivated to do more than the regular curriculum offers, the honors students, call for a specific pedagogical approach by teachers. The contribution 'Offering freedom as a teaching strategy for honors students' by Tineke Kingma, Marjolein Heijne-Penninga, and Marca Wolfensberger from both Windesheim University of Applied Sciences and from Hanze University of Applied Sciences Groningen, The Netherlands concentrates on the aspect of 'offering freedom' concerning teaching strategies that give students space for experimentation, risk-taking, personal initiatives, and pursuit of their interests (Wolfensberger, 2012). In this literature study, the authors elaborate on teaching behaviors that contribute to 'Offering Freedom.'

The second note focuses on 'Creating community' as a teaching strategy for honors students and can be considered as a sequel to the previous note about offering freedom. The authors Marjolein Heijne and Marca Wolfensberger are from Hanze University of Applied Sciences Groningen, The Netherlands. In this literature study about honors communities, they go after the teaching strategies that contribute to 'Creating community.' They argue that teachers seem to play a crucial role in facilitating the development of an honors community. The authors distinguish three clusters of teaching strategies that can foster the creation of a community: building an effective relationship between teachers and students, creating a 
positive and supportive spirit, and making the teacher part of the community in a practical and personal sense.

The third note, 'On student reflective portfolios in honors education,' is written by Merel van Goch from Utrecht University, The Netherlands. This note describes the use of portfolio reflections in undergraduate honors education to foster and assess the development of students throughout their honors education and their regular program. Students commonly reflect on their education and development at set times, and reflections are typically assessed formatively. The author describes the use of reflective portfolios in the Humanities Honours Programme at her university. By looking back and looking ahead at fixed moments in the students' curriculum, the portfolio forms a continuing element in students' study careers.

\section{Final remarks}

The practical perspective of many of the contributions to this issue shows the determination of those working in talent development and/or honors programs in higher education to learn from each other, share good practices, and critically reflect on how to challenge students who are willing and able to do more than the regular program offers.

The Journal of the European Honors Council aims to facilitate this process of learning from each other. Therefore, it is proudly published in full open access under a CC-BY license. This license means that the work can be shared as long as the source is credited. Authors retain copyright of their contributions. This policy is fully in line with the aims of the European Honors Council, facilitating an easily accessible platform for exchange of research insights and good practices. To further facilitate exchange, the European Honors Council invites you to become a member through its website, www.honorscouncil.eu. Membership is free, but you are asked to fill in a questionnaire about yourself and your institution.

The Editorial Board of the JEHC invites you to contribute to the next issue(s) of the Journal by sending in your papers and notes. In the next issue, we aim to focus on good practices. However, all contributions focusing on talent development in higher education are welcome. The call for contributions can be found on the website www.jehc.eu.

\section{References}

Wolfensberger, M. V. C. (2012). Teaching for Excellence. Honors Pedagogies revealed. Dissertation. Münster: Waxmann. 